\title{
REVIEW
}

\section{Understanding the Warburg effect and the prognostic value of stromal caveolin-1 as a marker of a lethal tumor microenvironment}

\author{
Federica Sotgia ${ }^{* 1,2,3}$, Ubaldo E Martinez-Outschoorn ${ }^{1,2,4}$, Stephanos Pavlides, ${ }^{1,2}$, Anthony Howell ${ }^{3}$, Richard G Pestell ${ }^{1,2,4}$ \\ and Michael P Lisanti*1,2,3,4
}

\begin{abstract}
Cancer cells show a broad spectrum of bioenergetic states, with some cells using aerobic glycolysis while others rely on oxidative phosphorylation as their main source of energy. In addition, there is mounting evidence that metabolic coupling occurs in aggressive tumors, between epithelial cancer cells and the stromal compartment, and between well-oxygenated and hypoxic compartments. We recently showed that oxidative stress in the tumor stroma, due to aerobic glycolysis and mitochondrial dysfunction, is important for cancer cell mutagenesis and tumor progression. More specifically, increased autophagy/mitophagy in the tumor stroma drives a form of parasitic epithelial-stromal metabolic coupling. These findings explain why it is effective to treat tumors with either inducers or inhibitors of autophagy, as both would disrupt this energetic coupling. We also discuss evidence that glutamine addiction in cancer cells produces ammonia via oxidative mitochondrial metabolism. Ammonia production in cancer cells, in turn, could then help maintain autophagy in the tumor stromal compartment. In this vicious cycle, the initial glutamine provided to cancer cells would be produced by autophagy in the tumor stroma. Thus, we believe that parasitic epithelial-stromal metabolic coupling has important implications for cancer diagnosis and therapy, for example, in designing novel metabolic imaging techniques and establishing new targeted therapies. In direct support of this notion, we identified a loss of stromal caveolin-1 as a marker of oxidative stress, hypoxia, and autophagy in the tumor microenvironment, explaining its powerful predictive value. Loss of stromal caveolin-1 in breast cancers is associated with early tumor recurrence, metastasis, and drug resistance, leading to poor clinical outcome.
\end{abstract}

\section{The conventional 'Warburg effect' versus oxidative mitochondrial metabolism}

The Warburg effect, also known as aerobic glycolysis, is defined as the propensity of cancer cells to take up high levels of glucose and to secrete lactate in the presence of oxygen. Warburg's original work indicated that while glucose uptake and lactate production are greatly elevated, a cancer cell's rate of mitochondrial respiration is similar to that of normal cells [1,2]. He, however, described it as a 'respiratory impairment' due to the fact that, in cancer cells, mitochondrial respiration is smaller, relative to their glycolytic power, but not smaller relative

\footnotetext{
*Correspondence: federica.sotgia@jefferson.edu;

michael.lisanti@kimmelcancercenter.org

'The Jefferson Stem Cell Biology and Regenerative Medicine Center, Philadelphia, PA 19107, USA

Full list of author information is available at the end of the article
}

to normal cells. He recognized that oxygen consumption is not diminished in tumor cells, but that respiration is disturbed because glycolysis persists in the presence of oxygen $[1,2]$. Unfortunately, the perception of his original findings was simplified over the years, and most subsequent papers validated that cancer cells undergo aerobic glycolysis and produce lactate, but did not measure mitochondrial respiration, and just presumed decreased tricarboxylic acid (TCA) cycle activity and reduced oxidative phosphorylation [1,2]. It is indeed well documented that, as a consequence of intra-tumoral hypoxia, the hypoxia-inducible factor (HIF) $1 \alpha$ pathway is activated in many tumors cells, resulting in the direct up-regulation of lactate dehydrogenase (LDH) and increased glucose consumption. For updated reviews on the Warburg effect, the reader is encouraged to refer to the following papers $[3,4]$.

However, new findings compel us to reconsider the current model of cancer cell metabolism. First, not all tumors are associated with increased aerobic glycolysis, 
and in fact it is now clear that cancer cells utilize both glycolysis and oxidative phosphorylation to satisfy their metabolic needs. Experimental assessments of ATP production in cancer cells have demonstrated that oxidative pathways play a significant role in energy generation, and may be responsible for about 50 to $80 \%$ of the ATP generated [5-8]. Also, it should be considered that most studies were performed using isolated cancer cells, which may behave very differently from cancer cells in vivo, surrounded by their natural microenvironment [9] (see also Koukourakis and colleagues [10] for another viewpoint).

Second, several studies now clearly indicate that mitochondrial activity and oxidative phosphorylation support tumor growth. Loss-of-function mutations in the TCA cycle gene IDH1 (isocitrate dehydrogenase 1) are found in about $70 \%$ of gliomas, but, interestingly, correlate with a better prognosis and improved survival, suggesting that severely decreased activity in one of the TCA cycle enzymes does not favor tumor aggressiveness [11]. The mitochondrial protein $\mathrm{p} 32$ was shown to maintain high levels of oxidative phosphorylation in human cancer cells and to sustain tumorigenicity in vivo [12]. In addition, STAT3 is known to enhance tumor growth and to predict poor prognosis in human cancers [13]. Interestingly, a pool of STAT3 localizes to the mitochondria, to sustain high levels of mitochondrial respiration [14] and to augment transformation by oncogenic Ras $[15,16]$. Similarly, the mitochondrial transcription factor A (TFAM), which is required for mitochondrial DNA replication and oxidative phosphorylation, is also required for K-Rasinduced lung tumorigenesis [17]. Finally, when constrained to use glycolysis by depletion of mitochondrial DNA, melanoma B16 cells $\left(B 16 \rho^{\circ}\right)$ and breast cancer T47D cells $\left(\mathrm{T} 47 \mathrm{D} \rho^{0}\right)$, show severe impairment of tumorigenicity in vivo $[18,19]$.

There is also evidence that pro-oncogenic molecules regulate mitochondrial function. Cyclin D1 inhibits mitochondrial function in breast cancer cells [20]. Overexpression of cyclin D1 is observed in about $50 \%$ of invasive breast cancers and is associated with a good clinical outcome [21], indicating that inhibition of mitochondrial activity correlates with favorable prognosis. Importantly, it was shown that the oncogene c-Myc stimulates mitochondrial biogenesis, and enhances glutamine metabolism by regulating the expression of mitochondrial glutaminase, the first enzyme in the glutamine utilization pathway [22]. Glutamine is an essential metabolic fuel that is converted to alpha-ketoglutarate and serves as a substrate for the TCA cycle or for glutathione synthesis, to promote energy production and cellular biosynthesis, and to protect against oxidative stress [23]. Interestingly, pharmacological targeting of mitochondrial glutaminase inhibits cancer cell transforming activity, suggesting that glutamine metabolism and its role in fueling and replenishing the TCA cycle are required for neoplastic transformation [24] (for a recent review on glutamine cancer metabolism, see [2]).

\section{The reverse Warburg effect}

It is increasingly apparent that the tumor microenvironment regulates neoplastic growth and progression. Activation of the stroma is a critical step required for tumor formation. Among the stromal players, cancer associated fibroblasts (CAFs) have recently taken center stage [25]. CAFs are activated, contractile fibroblasts that display features of myo-fibroblasts, express musclespecific actin, and show an increased ability to secrete and remodel the extracellular matrix [26,27]. They are not just neutral spectators, but actively support malignant transformation [28] and metastasis [29], as compared to normal resting fibroblasts. For example, in a humanized mouse model of breast cancer, oncogenically driven human organoids develop tumors only if coinjected with immortalized fibroblasts and not with normal primary fibroblasts, suggesting that stromal activation is required for breast cancer formation [30].

Importantly, the tumor stroma dictates clinical outcome and constitutes a source of potential biomarkers [31]. Expression profiling has identified a cancer-associated stromal signature that predicts good and poor clinical prognosis in breast cancer patients, independently of other factors [32-34].

We and others have recently shown that a loss of caveolin-1 (Cav-1) in the stromal compartment is a novel biomarker for predicting poor clinical outcome in all of the most common subtypes of human breast cancer, including the more lethal triple negative subtype $[35,36]$. A loss of stromal Cav-1 predicts early tumor recurrence, lymphnode metastasis, tamoxifen-resistance, and poor survival. Overall, breast cancer patients with a loss of stromal Cav-1 show a $20 \% 5$-year survival rate, compared to the $80 \%$ 5 -year survival of patients with high stromal Cav-1 expression. In triple negative patients, the 5-year survival rate is $75.5 \%$ for high stromal Cav-1 versus 9.4\% for absent stromal Cav-1 [37]. A loss of stromal Cav-1 also predicts progression to invasive disease in ductal carcinoma in situ patients, suggesting that a loss of Cav-1 regulates tumor progression [35]. Similarly, a loss of stromal Cav-1 is associated with advanced disease and metastasis, as well as a high Gleason score, in prostate cancer patients [38].

In order to mechanistically dissect how a loss of stromal Cav-1 induces a lethal microenvironment, we have employed Cav-1(-/-) null mice as a model system. Complementary studies were also performed with a coculture model of normal human fibroblasts and MCF7 breast cancer cells.

Unbiased proteomic and transcriptional analysis has shown that Cav-1(-/-) null bone-marrow-derived stromal 
cells display the up-regulation of both myo-fibroblast markers and glycolytic enzymes, clearly indicating that a loss of Cav-1 promotes myo-fibroblast conversion and induces aerobic glycolysis in stromal cells [39]. Thus, stromal cells lacking Cav-1 undergo aerobic glycolysis and secrete energy-rich metabolites (such as lactate and pyruvate) that directly feed cancer cells and fuel mitochondrial respiration of adjacent cancer cells. We have termed this novel hypothesis the 'reverse Warburg effect'. This novel idea has now also been independently confirmed by Pol and colleagues [40], who demonstrated that genetic ablation of Cav-1 in murine fibroblasts is indeed sufficient to functionally induce the onset of aerobic glycolysis via mitochondrial dysfunction [40]. Interestingly, immunohistochemistry on human breast cancers lacking stromal Cav-1 has demonstrated the over-expression of key glycolytic enzymes, such as PKM2 and LDH, in the fibroblastic tumor stroma [39].

In further support of this hypothesis, co-culture with cancer cells promotes Cav-1 down-regulation in adjacent fibroblasts. Importantly, when cultured under homotypic conditions, MCF7 cancer cells have a very low mitochondrial mass (the conventional Warburg effect). However, co-culture with fibroblasts, which more closely mirrors the microenvironment of a naturally occurring tumor, promotes a very significant increase in mitochondrial mass in MCF7 cancer cells, suggesting that the Warburg effect might be an in vitro artifact [41]. Importantly, lactate administration to homotypic MCF7 cancer cell cultures significantly increases mitochondrial mass, suggesting that lactate administration phenocopies the presence of reactive fibroblasts [41], by promoting mitochondrial biogenesis. These new data indicate that cancer cells and CAFs develop a 'symbiotic' or 'parasitic' relationship, with the vectorial and unilateral transfer of energy from glycolytic stromal cells to oxidative cancer cells (Figures 1 and 2).

Clinically, high glucose uptake has been exploited to monitor tumor growth using position emission tomography (PET) scanning via radiolabeled 2-deoxy-glucose. However, we should acknowledge that PET avidity does not necessarily correlate with high aerobic glycolysis. For example, PET is not useful in clear cell renal carcinomas $[42,43]$, which are the tumor 'prototype' in which the Warburg effect should sustain tumor formation. About half of clear cell renal carcinomas are due to mutations in the Von Hippel-Lindau (VHL) gene $[44,45]$, leading to HIF $1 \alpha$ constitutive activation and forced induction of aerobic glycolysis [46-48]. Conversely, little attention is paid to understanding which cell-type or compartments within a tumor are most PET avid. In fact, the clinical use of PET is well established in Hodgkin's lymphomas [49], which are composed of less than $10 \%$ tumor cells, the rest being stromal and inflammatory cells [50]. Yet, Hodgkin's

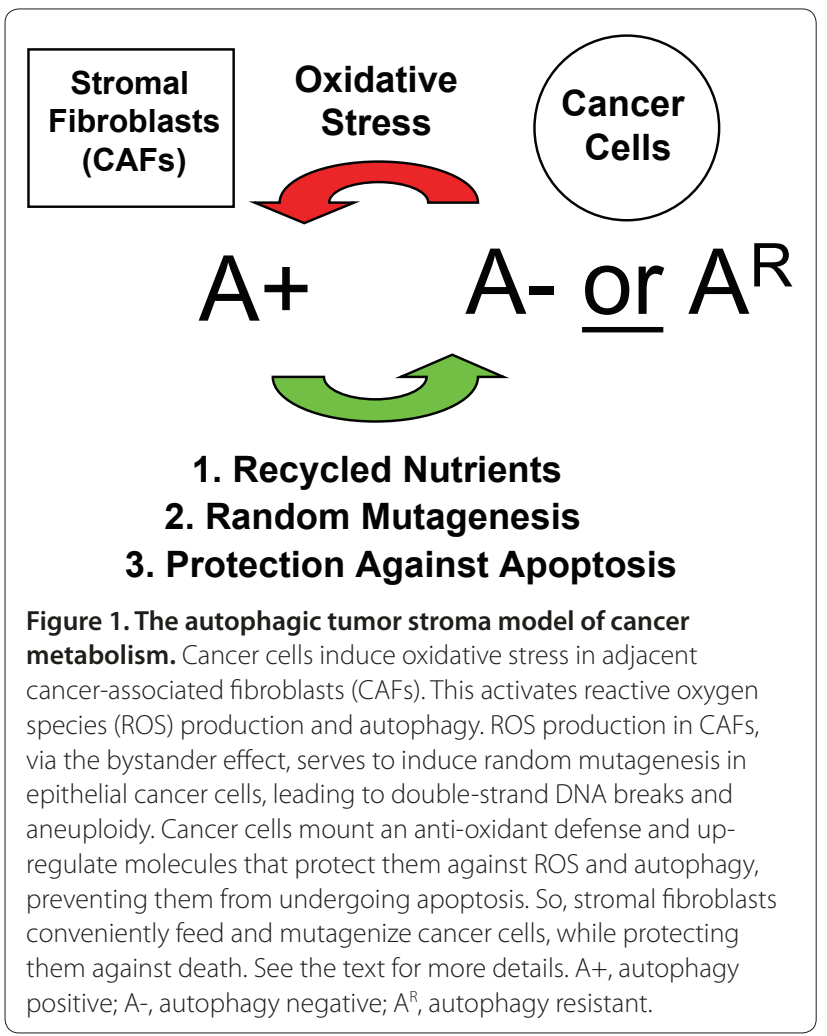

lymphomas are very PET avid tumors, suggesting that 2-deoxy-glucose uptake may be associated with the tumor stroma. That the fibrotic component may be glucose avid is further supported by the notion that PET is clinically used to assess the therapeutic response in gastrointestinal stromal tumors (GIST), which are a subset of tumors of mesenchymal origin. Finally, pilot clinical studies have shown that PET is useful for detection of various forms of fibrosis, including pulmonary fibrosis [51].

The reverse Warburg effect can also be described as 'metabolic coupling' between supporting glycolytic stromal cells and oxidative tumor cells. Metabolic cooperativity between adjacent cell-compartments is observed in several normal physiological settings. During folliculogenesis and early embryogenesis, oocytes are surrounded by supporting cumulus granulosa (CG) cells. Oocytes lack some crucial metabolic functions, such as the ability to utilize glucose, to produce cholesterol and to transport certain amino acids. Thus, oocytes control CG cell metabolism, promoting their glycolysis, cholesterol synthesis and amino acid uptake [52,53]. Remarkably, both oocytes and zygotes can reach a two-cell stage only in the presence of pyruvate and oxaloacetate, but not using glucose $[54,55]$. However, upon co-culture with CG cells, oocytes or zygotes can cleave to a two-cell stage also in the presence of glucose, clearly indicating that CG cells metabolize glucose and supply the oocyte with the 
(a)

\section{Stromal Fibroblasts}

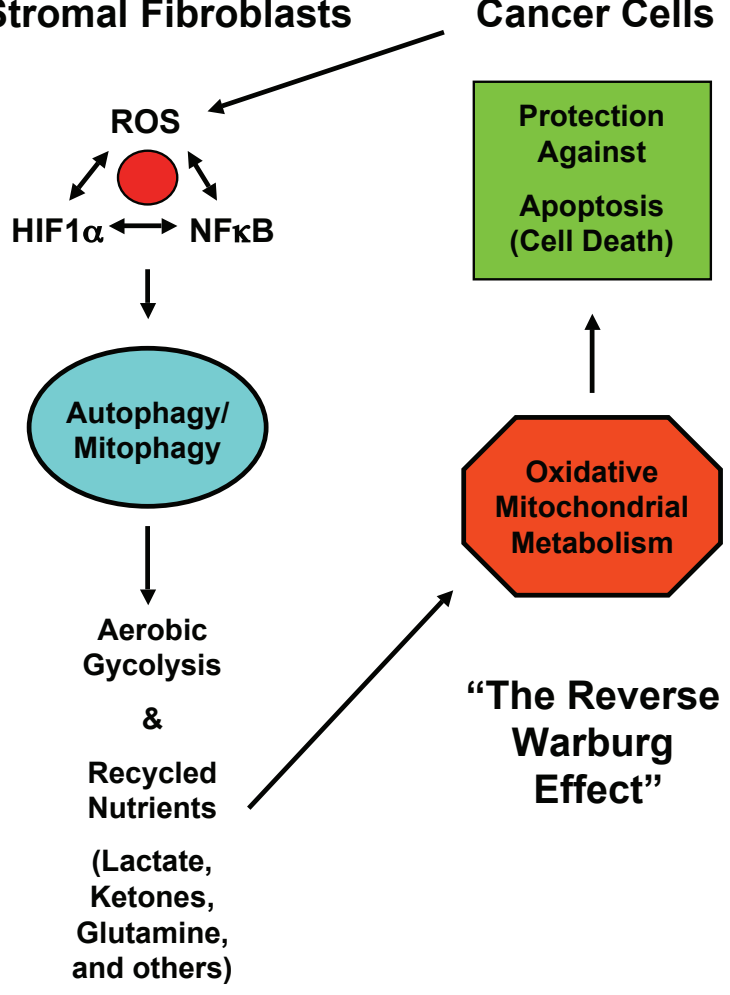

(b)
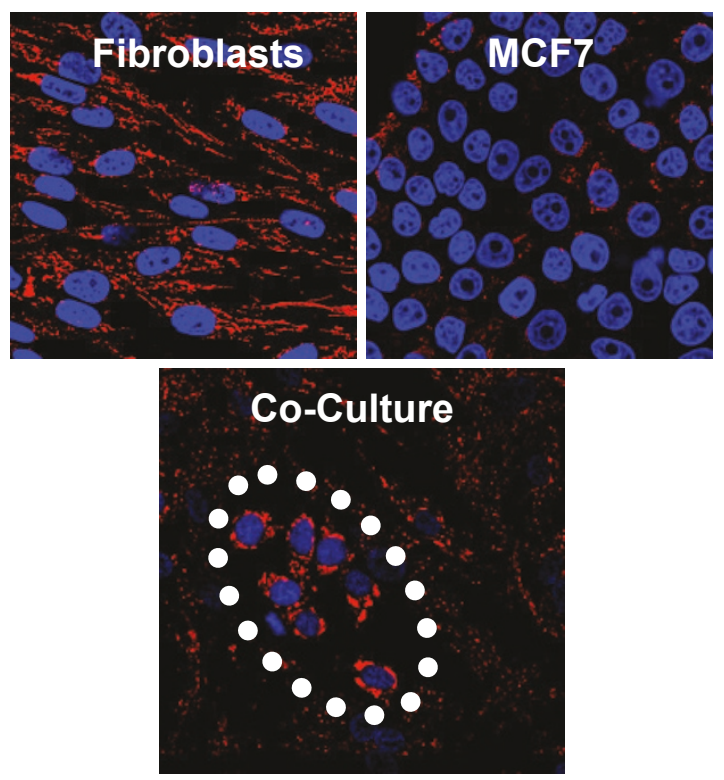

Figure 2. The reverse Warburg effect. (a) Via oxidative stress, cancer cells activate two major transcription factors in adjacent stromal fibroblasts (hypoxia-inducible factor (HIF)1 a and NFkB). This leads to the onset of both autophagy and mitophagy, as well as aerobic glycolysis, which then produces recycled nutrients (such as lactate, ketones, and glutamine). These high-energy chemical building blocks can then be transferred and used as fuel in the tricarboxylic acid cycle (TCA) in adjacent cancer cells. The outcome is high ATP production in cancer cells, and protection against cell death. ROS, reactive oxygen species. (b) Homotypic cultures (upper panels) of MCF7 cells (right) and hTERT-fibroblasts (left) were immunostained with a mitochondrial membrane antibody (red). Note that mitochondrial mass is lower in mono-cultures of MCF7 cells compared to fibroblasts. However, co-culture of MCF7 cells with fibroblasts (lower panel) induces a dramatic increase in mitochondrial mass in the 'central MCF7 cell colony', outlined by the dotted white oval. In contrast, mitochondrial mass is decreased in co-cultured fibroblasts. Panel (b) was modified and reproduced with permission from $[41,78]$.

glycolytic product pyruvate to permit maturation [54]. In this regard, transcriptional profiling of CG cells and oocytes has revealed that key enzymes of the glycolytic pathway (aldolase A, enolase 1, LDHA, and PKM2) are very highly expressed in CG cells, but are undetectable in oocytes [56]. These results indicate that granulosa cells support the development and maturation of oocytes and early embryos by providing them with essential nutrients, such as oxidative phosphorylation substrates (pyruvate and lactate [57]), amino acids [58], and cholesterol [59].

Metabolic coupling is also normally observed in the brain between astrocytes and neurons, and this is known as 'neuron-glia metabolic coupling' [60,61]. In this regard, glycolytic astrocytes generate high levels of lactate to support mitochondrial oxidative phosphorylation in adjacent neurons. Consistent with this idea, LDH is preferentially expressed in astrocytes, and the mitochondrial enzyme pyruvate dehydrogenase is present selectively within the neurons $[62,63]$. Also, in skeletal muscle it is well established that glycolytic fast-twitch muscle fibers produce lactate, which is then secreted via monocarboxylate transporter (MCT) 4. Lactate is then taken up by the slow-twitch fibers expressing MCT1 and utilized as a substrate for oxidative phosphorylation $[64,65]$. This form of metabolic coupling is known as the 'skeletal muscle lactate shuttle' [66].

As such, it is perhaps not surprising that tumors may have also developed a form of metabolic coupling, specifically involving tumor-stromal interactions. In further support of the existence of a 'lactate shuttle' in human tumors, we have now shown that CAFs express MCT4 (for lactate extrusion), while breast cancer cells express MCT1 (for lactate uptake) (Figure 3) [67]. Interestingly, MCT4 expression in CAFs is induced by oxidative stress, and MCT4 is a known HIF1 $\alpha$ target gene (see Discussion below) [67]. 

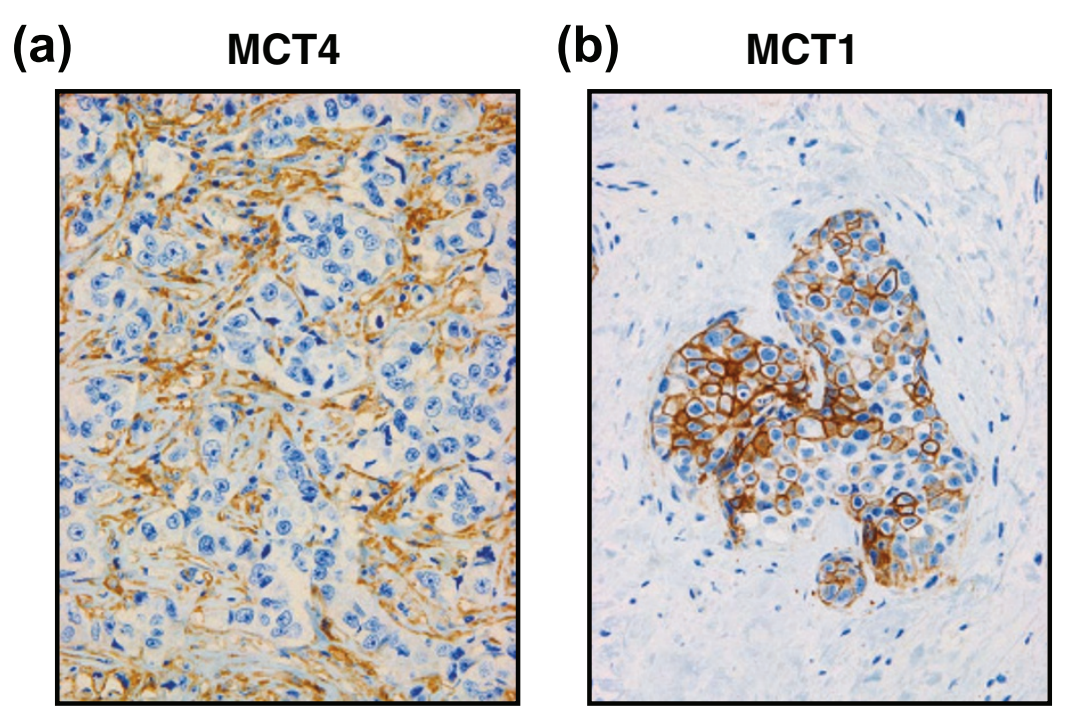

(c)

\section{ENERGY TRANSFER MECHANISM}

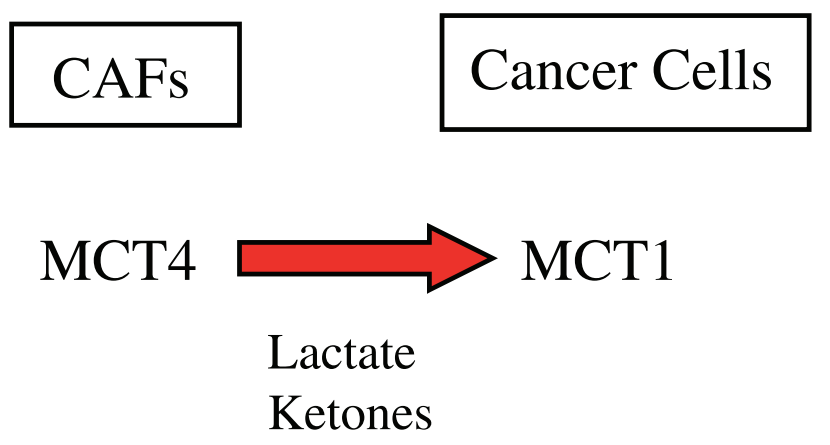

Figure 3. Evidence supporting a 'lactate shuttle' in human tumors: compartmentalized distribution of monocarboxylate transporter (MCT)1/4. (a) MCT4 is expressed in the fibroblastic stromal compartment of human breast cancers. Note that MCT4 staining is absent from the tumor epithelial cells, but is present in the surrounding stroma. MCT4 staining outlines the cancer-associated fibroblasts that surround nests of epithelial cancer cells. (b) MCT1 is expressed in the epithelial compartment of human breast cancers. Note that MCT1 staining is present in the tumor epithelial cells, but is absent in the surrounding stroma. (c) The lactate shuttle: an energy transfer mechanism in normal tissue and human cancers. MCT4 functions primarily as a transporter that extrudes lactate from cells that are undergoing aerobic glycolysis and lack functional mitochondria. After lactate is extruded by MCT4 in cancer-associated fibroblasts (CAFs), lactate is then taken up by MCT1 in adjacent cancer cells. Similarly, ketones are transported by the same MCTs that handle lactate. Our studies suggest that metabolic coupling occurs between CAFs and adjacent tumor cells. Modified and reproduced with permission from [67].

\section{Oxidative stress: random mutagenesis and protection against cell death}

Recent studies have dissected the mechanism(s) by which a loss of stromal Cav-1 leads to an aggressive breast cancer phenotype, and have shown that oxidative stress plays a central role. The role of oxidative stress in sustaining tumor growth is underscored by the observation that reactive oxygen species (ROS)-mediated myo-fibroblast conversion is sufficient to reduce tumor-free survival, and increases metastatic potential in a mammary tumor mouse model [68].
Gene expression profiling of Cav-1(-/-) null bonemarrow-derived stromal cells has shown the upregulation of gene transcripts associated with ROS production, and over-expression of the transcriptional targets of HIF $1 \alpha$ and NFKB, suggesting that a loss of stromal Cav-1 induces oxidative stress, mimics hypoxia, and stimulates inflammation [41].

Co-cultures of normal human fibroblasts and MCF7 cells indicate that cancer cells use oxidative stress as a weapon to trigger the conversion of adjacent fibroblasts into myo-fibroblasts [69]. Cancer cell-induced oxidative 
stress potently perturbs the behavior of adjacent fibroblasts, induces the lysosomal-mediated degradation of Cav-1, and promotes mitochondrial dysfunction, resulting in increased aerobic glycolysis [41]. In turn, these glycolytic fibroblasts support tumor cell mitochondrial respiration and growth by actively transferring highenergy nutrients (such as lactate and pyruvate) to cancer cells.

In support of the 'reverse Warburg effect', comparison of the tumor-promoting properties of two fibroblast lines (named CL3 and CL4) with either mitochondrial or glycolytic metabolism has revealed that aerobic glycolysis in CAFs greatly promotes tumor formation. CL3 fibroblasts show oxidative metabolism and increased mitochondrial mass, whereas CL4 fibroblasts display a shift towards aerobic glycolysis and increased lactate production [70]. Interestingly, in a xenograft model, CL4 fibroblasts enhance the growth of mammary tumors by approximately eight-fold compared to CL3 cells, without a detectable increase in angiogenesis. Consistent with this growth-promoting effect, CL4 fibroblasts also increase the mitochondrial mass of co-cultured breast cancer cells [71].

An oxidative-stress-rich micro-environment generates DNA damage in both cancer and stromal cells (Figure 1). We have shown that MCF7 cancer cells induce oxidative stress and promote DNA double-strand breaks in associated stromal cells, which are blocked by antioxidant treatments [41]. Similarly, after three-dimensional co-culture with prostate cancer cells, bone-derived stromal cells undergo stable cytogenetic modifications by a ROS-mediated mechanism [72].

Conversely, in an MCF7-fibroblast co-culture model, MCF7 cancer cells undergo aneuploidy and random mutagenesis [41], suggesting that CAFs facilitate the dynamic search for a more aggressive 'mutator phenotype' in cancer cells (Figure 1). Functionally, fibroblasts provide cancer cells with a six-fold protection against cell death [41] (Figure 2), via the up-regulation of the antiapoptotic protein TIGAR [41]. Cav-1 knockdown fibroblasts provide even greater protection for cancer cells against apoptosis, clearly indicating that a loss of stromal Cav-1 in humans may greatly facilitate tumor growth by suppression of cancer cell death [41].

Thus, data supporting the 'reverse Warburg effect' indicate that cancer cells and fibroblasts are metabolically coupled and mutagenically co-evolving [41,73]. Cancer cells use oxidative stress to corrupt adjacent fibroblasts and to induce their metabolic re-programming [73]. In this way, fibroblasts secrete energy rich metabolites that facilitate cancer cell survival. In addition, fibroblasts promote mutagenesis of cancer cells, leading to a more aggressive 'aneuploid' phenotype $[41,73]$. Aneuploidy in cancer cells is known to be associated with poor clinical outcome.

\section{Hypoxia, autophagy, and mitophagy in the tumor stroma}

Metabolomic profiling reveals that Cav-1(-/-) null mammary fat pads display a highly catabolic metabolism, with the increased release of several metabolites, such as amino acids, ribose and nucleotides, and a shift towards gluconeogenesis, as well as mitochondrial dysfunction [74]. These changes are consistent with increased autophagy, mitophagy and aerobic glycolysis, all processes that are induced by oxidative stress [74]. Autophagy or 'self-eating' is the process by which cells degrade their own cellular components to survive during starvation or to eliminate damaged organelles after oxidative stress. Mitophagy, or mitochondrial-autophagy, is particularly important to remove damaged ROS-generating mitochondria.

An autophagy/mitophagy program is also triggered by hypoxia $[75,76]$. Hypoxia is a common feature of solid tumors, and promotes cancer progression, invasion and metastasis [77]. Interestingly, via induction of autophagy, hypoxia is sufficient to induce a dramatic loss of Cav-1 in fibroblasts. The hypoxia-induced loss of Cav-1 can be inhibited by the autophagy inhibitor chloroquine, or by pharmacological inhibition of HIF1 $\alpha[69,78]$. Conversely, small interfering RNA-mediated Cav-1 knock-down is sufficient to induce pseudo-hypoxia, with HIF1 $\alpha$ and $\mathrm{NF} \kappa \mathrm{B}$ activation, and to promote autophagy/mitophagy, as well as a loss of mitochondrial membrane potential in stromal cells [78]. These results indicate that a loss of stromal Cav-1 is a marker of hypoxia and oxidative stress. In a co-culture model, autophagy in cancer-associated fibroblasts was shown to promote tumor cell survival via the induction of the pro-autophagic HIF $1 \alpha$ and NFKB pathways in the tumor stromal microenvironment [78]. Finally, the mitophagy marker Bnip3L is selectively upregulated in the stroma of human breast cancers lacking Cav-1, but is notably absent from the adjacent breast cancer epithelial cells [78].

Another study has shown that cell-specific induction of autophagy by HIF1 $\alpha$ activation in fibroblasts or MDAMB-231 cells differentially affects tumor growth. In a xenograft model, HIF $1 \alpha$ activation in fibroblasts greatly enhances the tumorigenicity of co-injected MDA-MB-231 cells, whereas HIF1 $\alpha$ activation in MDA-MB-231 cancer cells suppresses tumor growth [79]. Importantly, in this experimental setting, the levels of tumor angiogenesis were unchanged. As HIF1 $\alpha$ triggers autophagy in both fibroblasts and cancer cells, these data demonstrate that the role of autophagy in driving tumor formation is celltype specific, and that stromal autophagy, and not cancer cell autophagy, favors tumor growth.

Several studies have demonstrated that the overexpression of autophagic markers, such as ATG16L and cathepsin $\mathrm{K}$ and $\mathrm{D}$, in the stroma and not in tumor cells 
predicts poor prognosis [80-82]. Similarly, loss of autophagic markers, such as Beclin 1, in tumor cells correlates with poor clinical outcome, suggesting that activation of an autophagic program in tumor cells reduces tumor aggressiveness [83].

Metabolome profiling of several types of human cancer tissues versus corresponding normal tissues have consistently shown that cancer tissues are highly catabolic, with the significant accumulation of many amino acids and TCA cycle metabolites $[84,85]$. The levels of reduced glutathione were decreased in primary and metastatic prostate cancers compared to benign adjacent prostate tissue, suggesting that aggressive disease is associated with increased oxidative stress [86]. Also, these data show that the tumor microenvironment has increased oxidative-stress-induced autophagy and increased catabolism.

Taken together, all these findings suggest an integrated model whereby a loss of stromal Cav-1 induces autophagy/ mitophagy in the tumor stroma, via oxidative stress. This creates a catabolic micro-environment with the local accumulation of chemical building blocks and recycled nutrients (such as amino acids and nucleotides), directly feeding cancer cells to sustain their survival and growth. We have termed this novel idea the 'autophagic tumor stroma model of cancer' [74]. This new paradigm may explain the 'autophagy paradox', which is based on the fact that both the systemic inhibition and systemic stimulation of autophagy prevent tumor formation [87]. We propose that vectorial energy transfer from the tumor stroma to cancer cells directly sustains tumor growth, and that interruption of such metabolic coupling will block tumor growth. Autophagy inhibitors (such as chloroquine) functionally block the catabolic transfer of metabolites from the stroma to the tumor, inducing cancer cell starvation and death [88]. Conversely, autophagy inducers (such as rapamycin) promote autophagy in tumor cells and induce cell death [89]. Thus, both inhibitors and inducers of autophagy will have a similar effect by severing the metabolic coupling of the stroma and tumor cells, resulting in tumor growth inhibition (cutting 'off' the fuel supply).

This model may also explain why enthusiasm for antiangiogenic therapy has been dampened. In most cases, the clinical benefits are short term, and more importantly, new data suggest an unexpected link between anti-angiogenic treatments and metastasis. In pre-clinical models, anti-vascular endothelial growth factor (anti-VEGF) drugs (sunitinib and anti-VEGFR2 blocking antibodies) were shown to inhibit localized tumor formation, but potently induced relapse and metastasis [90-92]. Thus, by inducing hypoxia in the tumor microenvironment, antiangiogenic drugs may create a more favorable metastatic niche [93]. Hypoxia-induced autophagy may play a role by generating a catabolic micro-environment rich in chemical building blocks that can be directly used by cancer cells to sustain malignant transformation and metastatic progression.

Finally, the autophagic tumor stroma model can also provide an explanation for systemic cachexia, which is progressive skeletal muscle and adipose tissue wasting, affecting up to $50 \%$ of all cancer patients and resulting in severe weight loss and shortened survival [94]. Cachexia is the result of increased energy consumption and higher metabolic rates [95]. Based on our data, we envision that cancer leads to a generalized catabolic state via an autophagic-mechanism that generates building blocks and starves the rest of the body. While the exact signaling pathways governing this phenomenon are not yet fully elucidated, it is clear that oxidative stress-induced autophagy functions as a driver of muscle wasting [96]. For example, skeletal muscles from tumor-bearing mice showed impaired Akt activation and a more than 50-fold induction of Bnip3, a well recognized marker of autophagy/mitophagy [97]. These findings also help explain why patients with metabolic syndrome and diabetes have an increased risk for the development of multiple epithelial cancers, due to their constitutive and systemic activation of the autophagic program, and the over-production of high-energy nutrients, such as lactate and ketones [74].

We have recently used laser-capture micro-dissection of the tumor stroma from human breast cancers to directly validate that a loss of stromal Cav-1 is transcriptionally associated with oxidative stress, hypoxia, autophagy, and mitochondrial dysfunction, via gene-set enrichment analysis (Figure 4) [98]. In addition, we see that oxidative stress in CAFs induces cytokine production via $\mathrm{NF \kappa B}$ activation, directly linking inflammation with autophagy/catabolism in the tumor stroma [99]. So, cachexia may start locally as stromal autophagy, and then spread systemically via cytokine production and inflammation, which also drive autophagy [99].

\section{Glutamine utilization, ammonia production, and autophagy in the tumor stroma}

In direct support that cancer cells use mitochondrial oxidative metabolism, many investigators have shown that cancer cells are 'addicted' to glutamine $[24,100]$. Glutamine is a non-essential amino acid that is metabolized to glutamate and enters the TCA cycle as alphaketoglutarate, resulting in high ATP generation via oxidative phosphorylation [2,22,101-103].

Recent studies also show that ammonia is a by-product of glutaminolysis [104-106]. In addition, ammonia can act as a diffusible inducer of autophagy [104-106]. Given these observations, glutamine addiction in cancer cells provides another mechanism for driving and/or 


\title{
Stroma
}

(a)

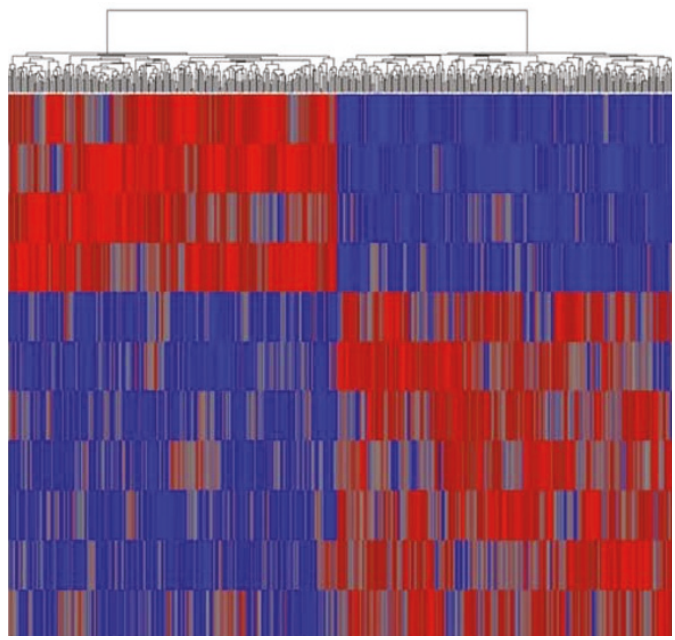

Cav-1 (+)

(b)

standardized Intensity

\author{
Cav-1 (-)
}

(c) Response to Hypoxia

Glycolysis and Pyruvate

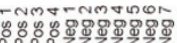

Metabolism

Luminal A samples separated by CAV1 signature expression
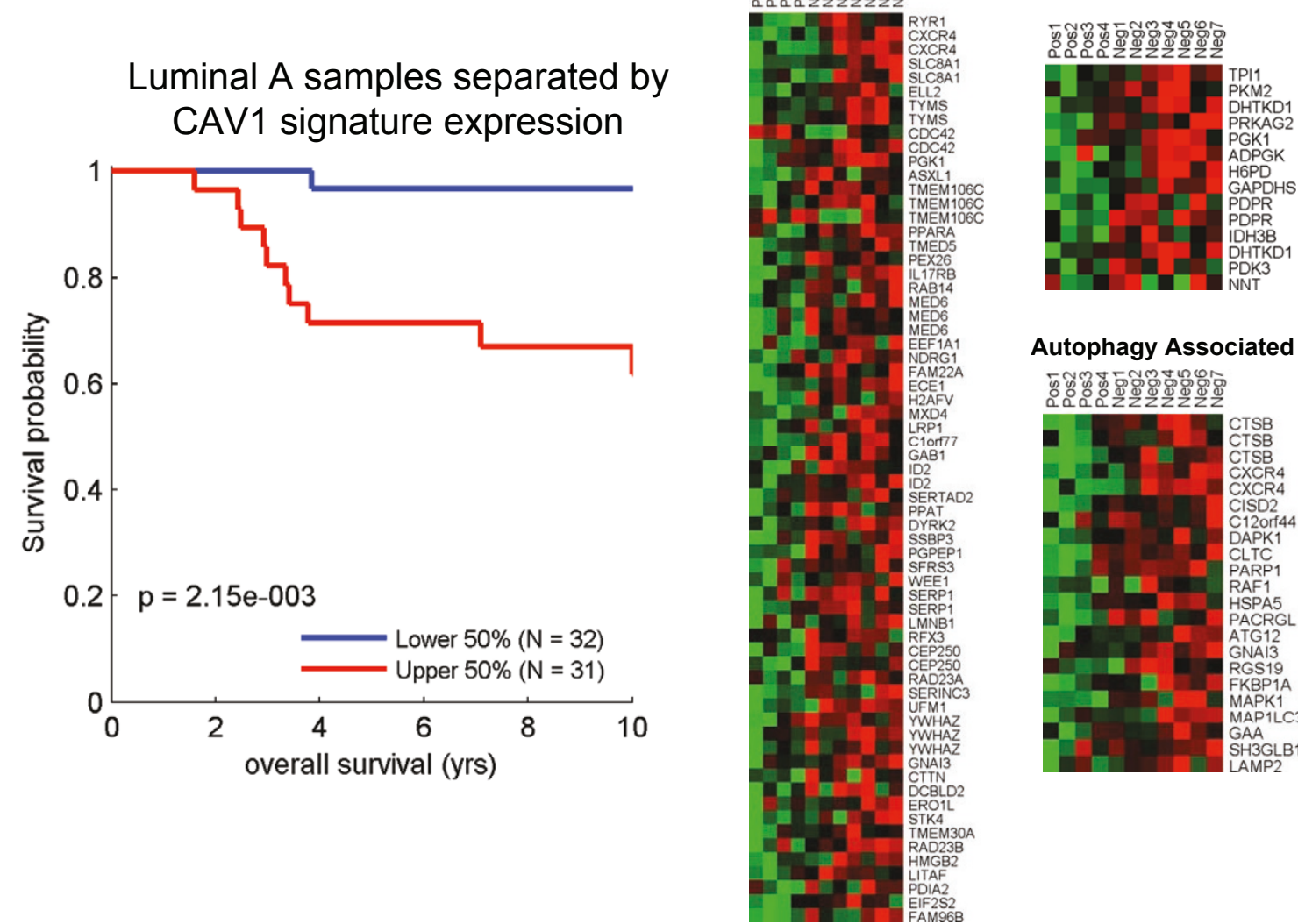

Autophagy Associated

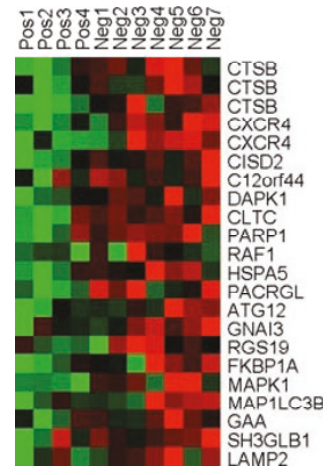

Figure 4. Molecular profiling of a Cav-1 deficient tumor micro-environment in breast cancer patients. (a) The transcriptional profiles of caveolin-1 (Cav-1)-positive (+) tumor stroma ( $N=4$ ) versus Cav-1-negative $(-)$ tumor stroma $(N=7)$ were compared, via laser-capture microdissection. We identified 238 gene transcripts that were up-regulated and 232 gene transcripts that were down-regulated in the stroma of tumors showing a loss of Cav-1 expression. Note that the two patient populations are transcriptionally distinct. (b) The Cav-1-deficient stromal gene signature is associated with poor survival in estrogen receptor-positive and luminal A breast cancer patients. Note that the Cav-1-deficient stromal signature is clearly associated with decreased overall survival. (c) Heat maps of the gene transcripts associated with the response to hypoxia, glycolysis, and autophagy. Note that Cav-1-deficient stroma shows the up-regulation of hypoxia target genes (65 transcripts), glycolysis/pyruvate metabolism (15 transcripts), and autophagy (22 transcripts). Modified and reproduced with permission from [98]. 
maintaining autophagy in the tumor micro-environment (Figure 5). In support of this idea, we have previously shown that a loss of Cav-1 in the stroma is sufficient to drive autophagy, resulting in increased glutamine production in the tumor micro-environment [74].

Thus, this concept defines a new vicious cycle in which autophagy in the tumor stroma transfers glutamine to cancer cells, and the by-product of this metabolism, ammonia, maintains autophagic glutamine production (Figure 5). This model fits well with the 'autophagic tumor stroma model of cancer metabolism', in which energyrich recycled nutrients (lactate, ketones, and glutamine) fuel oxidative mitochondrial metabolism in cancer cells.

\section{Lessons from other paradigms: an infectious parasitic cancer cell that metastasizes and captures mitochondrial DNA from host cells}

We have recently proposed that cancer cells behave like 'parasites', by inducing oxidative stress in normal host fibroblasts, resulting in the production of recycled nutrients via autophagy $[41,69,78]$. This is exactly the same mechanism by which infectious parasites (such as malaria) obtain nutrients and are propagated by inducing oxidative stress and autophagy in host cells [107-109]. In this regard, malaria is an 'intracellular' parasite, while cancer cells may be thought of as 'extracellular' parasites. This explains why chloroquine is both an effective antimalarial drug and an effective anti-tumor agent, as it functions as an autophagy inhibitor [110], cutting off the 'fuel supply' in both disease states.

Are there any examples of cancer cells that act as infectious parasites? Surprisingly, the answer is yes [111]. There are four known types: canine transmissible venereal tumor (CTVT), which is a sexually transmitted disease that occurs in feral dogs [112] - it is transmitted through coitus, licking/biting, or sniffing; devil facial tumor disease, spread among Tasmanian devils via facial biting [113,114]; contagious reticulum cell sarcoma, which is transmitted between Syrian hamsters via mosquito bites $[115,116]$; and malignant fibrous histiocytoma, which was transmitted from a cancer patient to his surgeon [117] during an injury that occurred when the surgeon was operating.

These parasitic cancers are all transmitted by allografting, so the cancer cells literally 'metastasize' from one affected host to another 'naïve' host, in an infectious manner that does not involve a virus.

Experimentally, the most is known about CTVT. This disease is thought to have originated in ancient wolves or coyotes, and the tumor cells themselves act as the infectious agent. As such, these cancer cells are genetically distinct from their hosts, as determined by genomic sequence analysis of their nuclear DNA [118]. CTVT represents the oldest known cancer cell line that

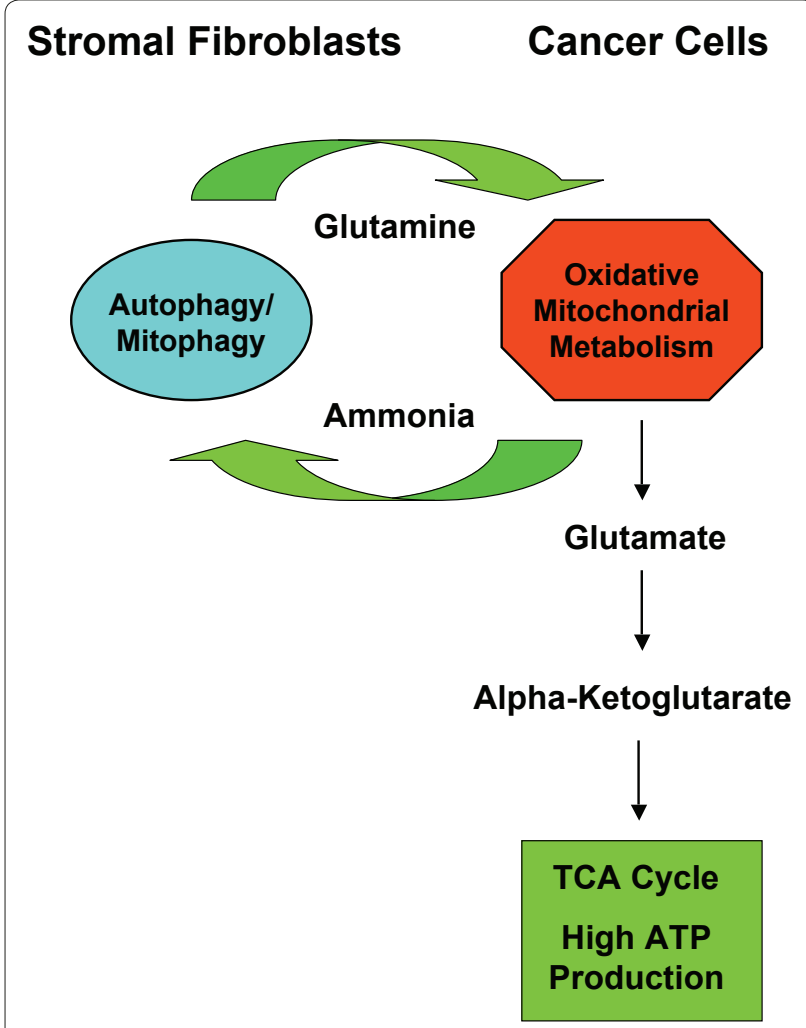

Figure 5. Glutamine utilization in cancer cells and the tumor stroma. Oxidative mitochondrial metabolism of glutamine in cancer cells produces ammonia. Ammonia production is sufficient to induce autophagy. Thus, autophagy in cancer-associated fibroblasts provides cancer cells with an abundant source of glutamine. In turn, the ammonia produced maintains the autophagic phenotype of the adjacent stromal fibroblasts. See text for details. TCA, tricarboxylic acid.

has been continuously propagated, most likely for more than 10,000 years $[118,119]$.

Interestingly, it has recently been shown that CTVT tumor cells survive by periodically 'capturing' mitochondrial DNA from their hosts $[119,120]$. Thus, it has been suggested that these CVCT tumor cells have survived for more than 10,000 years by maintaining and renewing their capacity for oxidative mitochondrial metabolism by 'stealing' host cell mitochondrial DNA [119,120]. In accordance with this idea, CTVT is highly sensitive to adriamycin/doxorubicin therapy [121], a chemo-therapeutic agent that also functions as a mitochondrial poison.

Similarly, it has been independently shown that human cancer cells can 'steal' live mitochondria or mitochondrial DNA [122] from adjacent mesenchymal stem cells in culture, which then rescues aerobic glycolysis in these cancer cells [122]. This is known as mitochondrial transfer [122]. Interestingly, others have shown that metastatic breast cancer cells show the up-regulation of numerous mitochondrial proteins [123], specifically 
(a)
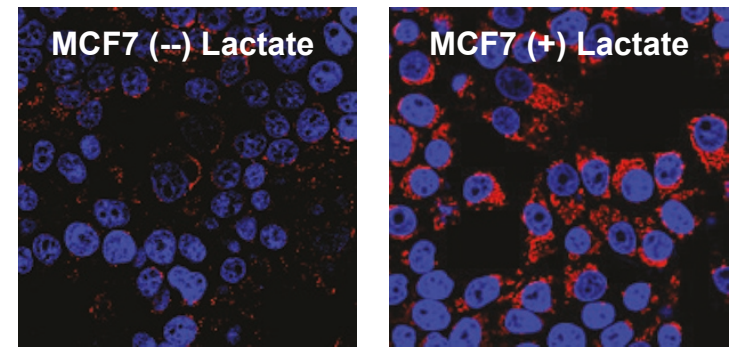

(b)

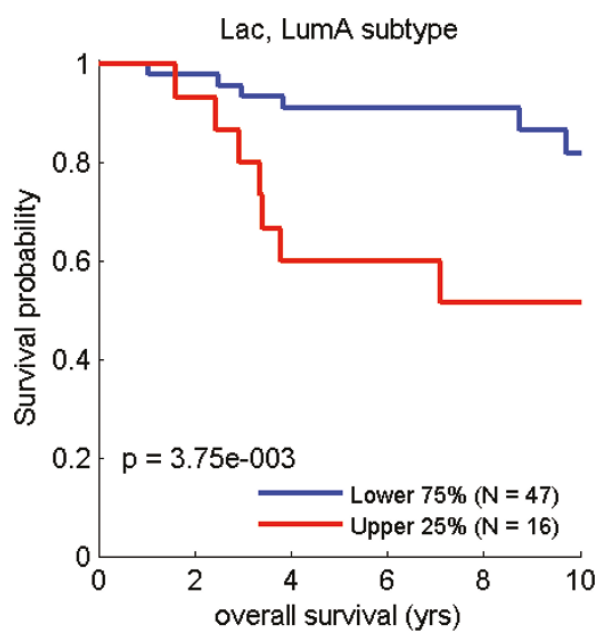

Figure 6. Lactate treatment of estrogen receptor-positive breast cancer cells drives mitochondrial biogenesis, leading to poor survival in a subset of luminal A breast cancer patients.

(a) Lactate-treated (10 mM) MCF7 cells show a significant increase in mitochondrial mass, as visualized by staining with antibodies against mitochondrial marker proteins. (b) Lactate-treated (10 mM) MCF7 cells were subjected to transcriptional profiling (exon-array) to generate a gene signature. Interestingly, this lactate-induced gene signature predicts poor clinical outcome in estrogen receptorpositive/luminal A breast cancer patients, which represent nearly 60 to $70 \%$ of cases, and is the most common type of breast cancer. Modified and reproduced with permission from [124].

associated with oxidative phosphorylation, as seen by unbiased proteomic analysis [123].

Thus, increased mitochondrial oxidative metabolism may be a key driver of tumor cell metastasis. In further support of this argument, treatment of MCF7 cancer cells with lactate is indeed sufficient to induce mitochondrial biogenesis in these cells [41,78] (Figure 6). To determine if these findings may be clinically relevant, a lactate-induced gene signature was recently generated using MCF7 cells [124]. This gene signature shows that lactate induces 'stemness' in cancer cells, and this lactateinduced gene signature predicts poor clinical outcome (including tumor recurrence and metastasis) in breast cancer patients [124] (Figure 6). These findings are consistent with experiments showing that intraperitoneal injection of lactate in an MDA-MB-231 xenograft model results in an approximately ten-fold increase in lung metastasis [125].

\section{Abbreviations}

CAF, cancer associated fibroblast; Cav, caveolin; CTVT, canine transmissible venereal tumor; HIF, hypoxia-inducible factor; LDH, lactate dehydrogenase; MCT, monocarboxylate transporter; NF, nuclear factor; PET, position emission tomography; ROS, reactive oxygen species; TCA, tricarboxylic acid.

\section{Competing interests}

The authors declare that they have no competing interests.

\section{Acknowledgements}

MPL and his laboratory were supported by grants from the $\mathrm{NIH} / \mathrm{NCI}(\mathrm{R} 01$ CA-080250; R01-CA-098779; R01-CA-120876; R01-AR-055660), and the Susan $G$ Komen Breast Cancer Foundation. FS was supported by grants from the WW Smith Charitable Trust, the Breast Cancer Alliance (BCA), and a Research Scholar Grant from the American Cancer Society (ACS). RGP was supported by grants from the NIH/NCI (R01-CA-70896, R01-CA-75503, R01-CA-86072, and R01-CA-107382) and the Dr Ralph and Marian C Falk Medical Research Trust. The Kimmel Cancer Center was supported by the NIH/NCI Cancer Center Core grant P30-CA-56036 (to RGP). Funds were also contributed by the Margaret Q Landenberger Research Foundation (to MPL). This project is funded, in part, under a grant with the Pennsylvania Department of Health (to MPL). The Department specifically disclaims responsibility for any analyses, interpretations or conclusions. This work was also supported, in part, by a Centre grant in Manchester from Breakthrough Breast Cancer in the UK (to $\mathrm{AH}$ ) and an Advanced ERC Grant from the European Research Council. Dr MP Lisanti would especially like to thank Drs Craig B Thompson, Tak W Mak, Michel L Tremblay, and Robert S DiPaola (other participants of the ASBMB/AACR 2011 Meetings) for their feedback, thoughtful comments, and helpful suggestions. This review was recently presented as a lecture at the AACR 2011 Meeting in the Educational Session 'Autophagy and Cell Death' on 2 April 2011 (Orlando, $\mathrm{FL}$ ). It was also presented as a lecture at the Experimental Biology 2011-ASBMB Meeting (Washington, DC) at the session on 'Metabolism and Cancer' on 13 April 2011.

\section{Author details}

'The Jefferson Stem Cell Biology and Regenerative Medicine Center, Philadelphia, PA 19107, USA. ²Departments of Stem Cell Biology and Regenerative Medicine, and Cancer Biology, Thomas Jefferson University, Philadelphia, PA 19107, USA. ${ }^{3}$ Manchester Breast Centre and Breakthrough Breast Cancer Research Unit, Paterson Institute for Cancer Research, Manchester, M20 4BX, UK. “'Department of Medical Oncology, Kimmel Cancer Center, Thomas Jefferson University, Philadelphia, PA 19107, USA.

Published: 8 July 2011

\section{References}

1. Warburg O: On the origin of cancer cells. Science 1956, 123:309-314.

2. Dang CV: PKM2 tyrosine phosphorylation and glutamine metabolism signal a different view of the Warburg effect. Sci Signal 2009, 2:pe75.

3. Cairns RA, Harris IS, Mak TW: Regulation of cancer cell metabolism. Nat Rev Cancer 2011, 11:85-95.

4. Deberardinis RJ, Sayed N, Ditsworth D, Thompson CB: Brick by brick: metabolism and tumor cell growth. Curr Opin Genet Dev 2008, 18:54-61.

5. Guppy M, Leedman P, Zu X, Russell V: Contribution by different fuels and metabolic pathways to the total ATP turnover of proliferating MCF-7 breast cancer cells. Biochem J 2002, 364:309-315.

6. Kallinowski F, Vaupel P, Runkel S, Berg G, Fortmeyer HP, Baessler KH, Wagner K, Mueller-Klieser W, Walenta S: Glucose uptake, lactate release, ketone body turnover, metabolic micromilieu, and $\mathrm{pH}$ distributions in human breast cancer xenografts in nude rats. Cancer Res 1988, 48:7264-7272.

7. Zu XL, Guppy M: Cancer metabolism: facts, fantasy, and fiction. Biochem Biophys Res Commun 2004, 313:459-465.

8. Kallinowski F, Schlenger KH, Runkel S, Kloes M, Stohrer M, Okunieff P, Vaupel P: Blood flow, metabolism, cellular microenvironment, and growth rate of human tumor xenografts. Cancer Res 1989, 49:3759-3764.

9. Gstraunthaler G, Seppi T, Pfaller W: Impact of culture conditions, culture 
media volumes, and glucose content on metabolic properties of renal epithelial cell cultures. Are renal cells in tissue culture hypoxic? Cell Physiol Biochem 1999, 9:150-172

10. Koukourakis MI, Giatromanolaki A, Harris AL, Sivridis E: Comparison of metabolic pathways between cancer cells and stromal cells in colorectal carcinomas: a metabolic survival role for tumor-associated stroma. Cancer Res 2006, 66:632-637.

11. Yan H, Parsons DW, Jin G, McLendon R, Rasheed BA, Yuan W, Kos I, BatinicHaberle I, Jones S, Riggins GJ, Friedman H, Friedman A, Reardon D, Herndon J, Kinzler KW, Velculescu VE, Vogelstein B, Bigner DD: IDH1 and IDH2 mutations in gliomas. N Engl J Med 2009, 360:765-773.

12. Fogal V, Richardson AD, Karmali PP, Scheffler IE, Smith JW, Ruoslahti E: Mitochondrial $\mathrm{p} 32$ protein is a critical regulator of tumor metabolism via maintenance of oxidative phosphorylation. Mol Cell Bio/ 2010 30:1303-1318.

13. Sheen-Chen SM, Huang CC, Tang RP, Chou FF, Eng HL: Prognostic value of signal transducers and activators of transcription 3 in breast cancer. Cancer Epidemiol Biomarkers Prev 2008, 17:2286-2290.

14. Wegrzyn J, Potla R, Chwae YJ, Sepuri NB, Zhang Q, Koeck T, Derecka M, Szczepanek K, Szelag M, Gornicka A, Moh A, Moghaddas S, Chen Q, Bobbili S, Cichy J, Dulak J, Baker DP, Wolfman A, Stuehr D, Hassan MO, Fu XY, Avadhani N, Drake Il, Fawcett P, Lesnefsky EJ, Larner AC: Function of mitochondrial Stat3 in cellular respiration. Science 2009, 323:793-797.

15. Reich NC: STAT3 revs up the powerhouse. Sci Signal 2009, 2:pe61.

16. Gough DJ, Corlett A, Schlessinger K, Wegrzyn J, Larner AC, Levy DE: Mitochondrial STAT3 supports Ras-dependent oncogenic transformation. Science 2009, 324:1713-1716.

17. Weinberg F, Hamanaka R, Wheaton WW, Weinberg S, Joseph J, Lopez M Kalyanaraman B, Mutlu GM, Budinger GR, Chandel NS: Mitochondrial metabolism and ROS generation are essential for Kras-mediated tumorigenicity. Proc Natl Acad Sci US A 2010, 107:8788-8793.

18. Berridge MV, Tan AS: Effects of mitochondrial gene deletion on tumorigenicity of metastatic melanoma: reassessing the Warburg effect. Rejuvenation Res 2010, 13:139-141

19. Yu M, Shi Y, Wei X, Yang Y, Zhou Y, Hao X, Zhang N, Niu R: Depletion of mitochondrial DNA by ethidium bromide treatment inhibits the proliferation and tumorigenesis of T47D human breast cancer cells. Toxicol Lett 2007, 170:83-93.

20. Sakamaki T, Casimiro MC, Ju X, Quong AA, Katiyar S, Liu M, Jiao X, Li A, Zhang X, Lu Y, Wang C, Byers S, Nicholson R, Link T, Shemluck M, Yang J, Fricke ST, Novikoff PM, Papanikolaou A, Arnold A, Albanese C, Pestell R: Cyclin D1 determines mitochondrial function in vivo. Mol Cell Biol 2006, 26:5449-5469.

21. Bostrom P, Soderstrom M, Palokangas T, Vahlberg T, Collan Y, Carpen O, Hirsimaki P: Analysis of cyclins A, B1, D1 and E in breast cancer in relation to tumour grade and other prognostic factors. BMC Res Notes 2009, 2:140.

22. Gao P, Tchernyshyov I, Chang TC, Lee YS, Kita K, Ochi T, Zeller KI, De Marzo AM, Van Eyk JE, Mendell JT, Dang CV: c-Myc suppression of miR-23a/b enhances mitochondrial glutaminase expression and glutamine metabolism. Nature 2009, 458:762-765

23. Wise DR, DeBerardinis RJ, Mancuso A, Sayed N, Zhang XY, Pfeiffer HK, Nissim I, Daikhin E, Yudkoff M, McMahon SB, Thompson CB: Myc regulates a transcriptional program that stimulates mitochondrial glutaminolysis and leads to glutamine addiction. Proc Natl Acad Sci U S A 2008, 105:18782-18787

24. Wang JB, Erickson JW, Fuji R, Ramachandran S, Gao P, Dinavahi R, Wilson KF, Ambrosio AL, Dias SM, Dang CV, Cerione RA: Targeting mitochondrial glutaminase activity inhibits oncogenic transformation. Cancer Cell 2010, 18:207-219.

25. Kalluri R, Zeisberg M: Fibroblasts in cancer. Nat Rev Cancer 2006, 6:392-401.

26. Ronnov-Jessen L, Petersen OW, Bissell MJ: Cellular changes involved in conversion of normal to malignant breast: importance of the stromal reaction. Physiol Rev 1996, 76:69-125.

27. Shekhar MP, Pauley R, Heppner G: Host microenvironment in breast cancer development: extracellular matrix-stromal cell contribution to neoplastic phenotype of epithelial cells in the breast. Breast Cancer Res 2003, 5:130-135.

28. Orimo A, Gupta PB, Sgroi DC, Arenzana-Seisdedos F, Delaunay T, Naeem R, Carey VJ, Richardson AL, Weinberg RA: Stromal fibroblasts present in invasive human breast carcinomas promote tumor growth and angiogenesis through elevated SDF-1/CXCL12 secretion. Cell 2005, 121:335-348.
29. Karnoub AE, Dash AB, Vo AP, Sullivan A, Brooks MW, Bell GW, Richardson AL, Polyak K, Tubo R, Weinberg RA: Mesenchymal stem cells within tumour stroma promote breast cancer metastasis. Nature 2007, 449:557-563.

30. Wu M, Jung L, Cooper AB, Fleet C, Chen L, Breault L, Clark K, Cai Z, Vincent S, Bottega S, Shen Q, Richardson A, Bosenburg M, Naber SP, DePinho RA, Kuperwasser C, Robinson MO: Dissecting genetic requirements of human breast tumorigenesis in a tissue transgenic model of human breast cancer in mice. Proc Natl Acad Sci U S A 2009, 106:7022-7027.

31. Howell A, Landberg $G$, Bergh J: Breast tumour stroma is a prognostic indicator and target for therapy. Breast Cancer Res 2009, 11 Suppl 3:S16.

32. Finak $G$, Bertos $N$, Pepin $F$, Sadekova S, Souleimanova M, Zhao H, Chen H, Omeroglu G, Meterissian S, Omeroglu A, Hallett M, Park M: Stromal gene expression predicts clinical outcome in breast cancer. Nat Med 2008, 14:518-527.

33. Ma XJ, Dahiya S, Richardson E, Erlander M, Sgroi DC: Gene expression profiling of the tumor microenvironment during breast cancer progression. Breast Cancer Res 2009, 11:R7.

34. Bianchini G, Qi Y, Alvarez RH, Iwamoto T, Coutant C, Ibrahim NK, Valero V, Cristofanilli M, Green MC, Radvanyi L, Hatzis C, Hortobagyi GN, Andre F, Gianni L, Symmans WF, Pusztai L: Molecular anatomy of breast cancer stroma and its prognostic value in estrogen receptor-positive and -negative cancers. J Clin Oncol 2010, 28:4316-4323.

35. Witkiewicz AK, Casimiro MC, Dasgupta A, Mercier I, Wang C, Bonuccelli G, Jasmin JF, Frank PG, Pestell RG, Kleer CG, Sotgia F, Lisanti MP: Towards a new "stromal-based" classification system for human breast cancer prognosis and therapy. Cell Cycle 2009, 8:1654-1658.

36. Sloan EK, Ciocca DR, Pouliot N, Natoli A, Restall C, Henderson MA, Fanelli MA, Cuello-Carrion FD, Gago FE, Anderson RL: Stromal cell expression of caveolin-1 predicts outcome in breast cancer. Am J Pathol 2009, 174:2035-2043.

37. Witkiewicz AK, Dasgupta A, Sammons S, Er O, Potoczek MB, Guiles F, Sotgia F, Brody JR, Mitchell EP, Lisanti MP: Loss of stromal caveolin-1 expression predicts poor clinical outcome in triple negative and basal-like breast cancers. Cancer Biol Ther 2010, 10:135-143.

38. Di Vizio D, Morello M, Sotgia F, Pestell RG, Freeman MR, Lisanti MP: An absence of stromal caveolin-1 is associated with advanced prostate cancer, metastatic disease and epithelial Akt activation. Cell Cycle 2009, 8:2420-2424.

39. Pavlides S, Whitaker-Menezes D, Castello-Cros R, Flomenberg N, Witkiewicz AK, Frank PG, Casimiro MC, Wang C, Fortina P, Addya S, Pestell RG, Martinez Outschoorn UE, Sotgia F, Lisanti MP: The reverse Warburg effect: aerobic glycolysis in cancer associated fibroblasts and the tumor stroma. Cell Cycle 2009, 8:3984-4001.

40. Bosch M, Marí M, Herms A, Fernández A, Fajardo A, Kassan A, Giralt A, Colell A, Balgoma D, Barbero E, González-Moreno E, Matias N, Tebar F, Balsinde J, Camps M, Enrich C, Gross SP, García-Ruiz C, Pérez-Navarro E, Fernández-Checa JC, Pol A: Caveolin-1 deficiency causes cholesterol-dependent mitochondrial dysfunction and apoptotic susceptibility. Curr Biol 2011 21:681-686.

41. Martinez-Outschoorn UE, Balliet RM, Rivadeneira DB, Chiavarina B, Pavlides S, Wang C, Whitaker-Menezes D, Daumer KM, Lin Z, Witkiewicz AK, Flomenberg N, Howell A, Pestell RG, Knudsen ES, Sotgia F, Lisanti MP: Oxidative stress in cancer associated fibroblasts drives tumor-stroma co-evolution: A new paradigm for understanding tumor metabolism, the field effect and genomic instability in cancer cells. Cell cycle 2010, 9:3256-3276.

42. Mueller-Lisse UG, Mueller-Lisse UL: Imaging of advanced renal cell carcinoma. World J Urol 2010, 28:253-261

43. Avril N, Dambha F, Murray I, Shamash J, Powles T, Sahdev A: The clinical advances of fluorine-2-D-deoxyglucose--positron emission tomography/ computed tomography in urological cancers. Int J Urol 2010, 17:501-511.

44. Gnarra JR, Tory K, Weng Y, Schmidt L, Wei MH, Li H, Latif F, Liu S, Chen F, Duh FM, et al:: Mutations of the VHL tumour suppressor gene in renal carcinoma. Nat Genet 1994, 7:85-90.

45. Cowey $\mathrm{CL}$, Rathmell WK: VHL gene mutations in renal cell carcinoma: role as a biomarker of disease outcome and drug efficacy. Curr Oncol Rep 2009, 11:94-101.

46. Tanimoto K, Makino Y, Pereira T, Poellinger $L$ : Mechanism of regulation of the hypoxia-inducible factor-1 alpha by the von Hippel-Lindau tumor suppressor protein. EMBO J 2000, 19:4298-4309.

47. Kamura T, Sato S, Iwai K, Czyzyk-Krzeska M, Conaway RC, Conaway JW Activation of HIF1alpha ubiquitination by a reconstituted von 
Hippel-Lindau (VHL) tumor suppressor complex. Proc Natl Acad Sci U S A 2000, 97:10430-10435.

48. Ohh M, Park CW, Ivan M, Hoffman MA, Kim TY, Huang LE, Pavletich N, Chau V, Kaelin WG: Ubiquitination of hypoxia-inducible factor requires direct binding to the beta-domain of the von Hippel-Lindau protein. Nat Cell Biol 2000, 2:423-427.

49. Weiler-Sagie M, Bushelev O, Epelbaum R, Dann EJ, Haim N, Avivi I, Ben-Barak A, Ben-Arie Y, Bar-Shalom R, Israel O: (18)F-FDG avidity in lymphoma readdressed: a study of 766 patients. J Nucl Med 2010, 51:25-30

50. Aldinucci D, Gloghini A, Pinto A, De Filippi R, Carbone A: The classical Hodgkin's lymphoma microenvironment and its role in promoting tumour growth and immune escape. J Pathol 2010, 221:248-263.

51. Groves AM, Win T, Screaton NJ, Berovic M, Endozo R, Booth H, Kayani I, Menezes LJ, Dickson JC, Ell PJ: Idiopathic pulmonary fibrosis and diffuse parenchymal lung disease: implications from initial experience with $18 \mathrm{~F}$ FDG PET/CT. J Nucl Med 2009, 50:538-545.

52. Su YQ, Sugiura K, Eppig JJ: Mouse oocyte control of granulosa cell development and function: paracrine regulation of cumulus cell metabolism. Semin Reprod Med 2009, 27:32-42.

53. Sugiura K, Su YQ, Diaz FJ, Pangas SA, Sharma S, Wigglesworth K, O'Brien MJ, Matzuk MM, Shimasaki S, Eppig JJ: Oocyte-derived BMP15 and FGFs cooperate to promote glycolysis in cumulus cells. Development 2007, 134:2593-2603

54. Biggers JD, Whittingham DG, Donahue RP: The pattern of energy metabolism in the mouse oocyte and zygote. Proc Natl Acad Sci US A 1967, 58:560-567.

55. Brinster RL: Studies on the development of mouse embryos in vitro. li. The effect of energy source. J Exp Zool 1965, 158:59-68.

56. Sugiura K, Pendola FL, Eppig JJ: Oocyte control of metabolic cooperativity between oocytes and companion granulosa cells: energy metabolism. Dev Biol 2005, 279:20-30.

57. Brinster RL: Oxidation of pyruvate and glucose by oocytes of the mouse and rhesus monkey. J Reprod Fertil 1971, 24:187-191.

58. Colonna R, Mangia F: Mechanisms of amino acid uptake in cumulusenclosed mouse oocytes. Biol Reprod 1983, 28:797-803.

59. Su YQ, Sugiura K, Wigglesworth K, O'Brien MJ, Affourtit JP, Pangas SA, Matzuk MM, Eppig JJ: Oocyte regulation of metabolic cooperativity between mouse cumulus cells and oocytes: BMP15 and GDF9 control cholesterol biosynthesis in cumulus cells. Development 2008, 135:111-121.

60. Tsacopoulos M, Magistretti PJ: Metabolic coupling between glia and neurons. J Neurosci 1996, 16:877-885.

61. Magistretti PJ, Pellerin L: Cellular mechanisms of brain energy metabolism. Relevance to functional brain imaging and to neurodegenerative disorders. Ann N Y Acad Sci 1996, 777:380-387.

62. Bittar PG, Charnay Y, Pellerin L, Bouras C, Magistretti PJ: Selective distribution of lactate dehydrogenase isoenzymes in neurons and astrocytes of human brain. J Cereb Blood Flow Metab 1996, 16:1079-1089.

63. Laughton JD, Bittar P, Charnay Y, Pellerin L, Kovari E, Magistretti PJ, Bouras C: Metabolic compartmentalization in the human cortex and hippocampus: evidence for a cell- and region-specific localization of lactate dehydrogenase 5 and pyruvate dehydrogenase. BMC Neurosci 2007, 8:35.

64. Connett RJ, Gayeski TE, Honig CR: Lactate accumulation in fully aerobic, working, dog gracilis muscle. Am J Physiol 1984, 246:H120-128.

65. McCullagh KJ, Poole RC, Halestrap AP, Tipton KF, O'Brien M, Bonen A: Chronic electrical stimulation increases MCT1 and lactate uptake in red and white skeletal muscle. Am J Physio/ 1997, 273:E239-246.

66. Brooks GA: The lactate shuttle during exercise and recovery. Med Sci Sports Exerc 1986, 18:360-368.

67. Whitaker-Menezes D, Martinez-Outschoorn UE, Lin Z, Ertel A, Flomenberg N, Witkiewicz AK, Birbe RC, Howell A, Pavlides S, Gandara R, Pestell RG, Sotgia F, Philp NJ, Lisanti MP: Evidence for a stromal-epithelial 'lactate shuttle' in human tumors: MCT4 is a marker of oxidative stress in cancer-associated fibroblasts. Cell Cycle 2011, 10:1772-1783.

68. Toullec A, Gerald D, Despouy G, Bourachot B, Cardon M, Lefort S, Richardson M, Rigaill G, Parrini MC, Lucchesi C, Bellanger D, Stern MH, Dubois T, SastreGarau X, Delattre O, Vincent-Salomon A, Mechta-Grigoriou F: Oxidative stress promotes myofibroblast differentiation and tumour spreading. EMBOMOl Med 2010, 2:211-230

69. Martinez-Outschoorn UE, Pavlides S, Whitaker-Menezes D, Daumer KM, Milliman JN, Chiavarina B, Migneco G, Witkiewicz AK, Martinez-Cantarin MP, Flomenberg N, Howell A, Pestell RG, Lisanti MP, Sotgia F: Tumor cells induce the cancer associated fibroblast phenotype via caveolin-1 degradation: Implications for breast cancer and DCIS therapy with autophagy inhibitors. Cell Cycle 2010, 9:2423-2433.

70. Ramanathan A, Wang C, Schreiber SL: Perturbational profiling of a cell-line model of tumorigenesis by using metabolic measurements. Proc Natl Acad SciUS A 2005, 102:5992-5997.

71. Migneco G, Whitaker-Menezes D, Chiavarina B, Castello-Cros R, Pavlides S, Pestell RG, Fatatis A, Flomenberg N, Tsirigos A, Howell A, MartinezOutschoorn UE, Sotgia F, Lisanti MP: Glycolytic cancer associated fibroblasts promote breast cancer tumor growth, without a measurable increase in angiogenesis: Evidence for stromal-epithelial metabolic coupling. Cell Cycle 2010, 9:2412-2422.

72. Sung SY, Hsieh CL, Law A, Zhau HE, Pathak S, Multani AS, Lim S, Coleman IM, Wu LC, Figg WD, Dahut WL, Nelson P, Lee JK, Amin MB, Lyles R, Johnstone PA, Marshall FF, Chung LW: Coevolution of prostate cancer and bone stroma in three-dimensional coculture: implications for cancer growth and metastasis. Cancer Res 2008, 68:9996-10003.

73. Lisanti MP, Martinez-Outschoorn UE, Chiavarina B, Pavlides S, WhitakerMenezes D, Tsirigos A, Witkiewicz A, Lin Z, Balliet R, Howell A, Sotgia F: Understanding the "lethal" drivers of tumor-stroma co-evolution: emerging role(s) for hypoxia, oxidative stress and autophagy/mitophagy in the tumor micro-environment. Cancer Biol Ther 2011, 10:537-542.

74. Pavlides S, Tsirigos A, Migneco G, Whitaker-Menezes D, Chiavarina B, Flomenberg N, Frank PG, Casimiro MC, Wang C, Pestell RG, MartinezOutschoorn UE, Howell A, Sotgia F, Lisanti MP: The autophagic tumor stroma model of cancer: Role of oxidative stress and ketone production in fueling tumor cell metabolism. Cell Cycle 2010, 9:3485-3505.

75. Azad MB, Gibson SB: Role of BNIP3 in proliferation and hypoxia-induced autophagy: implications for personalized cancer therapies. Ann N Y Acad Sci 2010, 1210:8-16

76. Kume S, Uzu T, Horiike K, Chin-Kanasaki M, Isshiki K, Araki S, Sugimoto T, Haneda M, Kashiwagi A, Koya D: Calorie restriction enhances cell adaptation to hypoxia through Sirt1-dependent mitochondrial autophagy in mouse aged kidney. J Clin Invest 2010, 120:1043-1055.

77. Pennacchietti S, Michieli P, Galluzzo M, Mazzone M, Giordano S, Comoglio PM: Hypoxia promotes invasive growth by transcriptional activation of the met protooncogene. Cancer Cell 2003, 3:347-361.

78. Martinez-Outschoorn UE, Trimmer C, Lin Z, Whitaker-Menezes D, Chiavarina B, Zhou J, Wang C, Pavlides S, Martinez-Cantarin MP, Capozza F, Witkiewicz AK, Flomenberg N, Howell A, Pestell RG, Caro J, Lisanti MP, Sotgia F: Autophagy in cancer associated fibroblasts promotes tumor cell survival: Role of hypoxia, HIF1 induction and NFkappaB activation in the tumor stromal microenvironment. Cell Cycle 2010, 9:3515-3533.

79. Chiavarina B, Whitaker-Menezes D, Migneco G, Martinez-Outschoorn UE, Pavlides S, Howell A, Tanowitz HB, Casimiro MC, Wang C, Pestell RG, Grieshaber P, Caro J, Sotgia F, Lisanti MP: HIF1-alpha functions as a tumor promoter in cancer associated fibroblasts, and as a tumor suppressor in breast cancer cells: Autophagy drives compartment-specific oncogenesis. Cell Cycle 2010, 9:3534-3551.

80. Nomura H, Uzawa K, Yamano Y, Fushimi K, Ishigami T, Kouzu Y, Koike H, Siiba M, Bukawa $H$, Yokoe $H$, Kubosawa $H$, Tanzawa $H$ : Overexpression and altered subcellular localization of autophagy-related 16-like 1 in human oral squamous-cell carcinoma: correlation with lymphovascular invasion and lymph-node metastasis. Hum Pathol 2009, 40:83-91.

81. Nadji M, Fresno M, Nassiri M, Conner G, Herrero A, Morales AR: Cathepsin D in host stromal cells, but not in tumor cells, is associated with aggressive behavior in node-negative breast cancer. Hum Pathol 1996, 27:890-895.

82. Kleer CG, Bloushtain-Qimron N, Chen YH, Carrasco D, Hu M, Yao J, Kraeft SK, Collins LC, Sabel MS, Argani P, Gelman R, Schnitt SJ, Krop IE, Polyak K: Epithelial and stromal cathepsin K and CXCL14 expression in breast tumor progression. Clin Cancer Res 2008, 14:5357-5367.

83. Levine B, Kroemer G: Autophagy in the pathogenesis of disease. Cell 2008, $132: 27-42$

84. Denkert C, Budczies J, Kind T, Weichert W, Tablack P, Sehouli J, Niesporek S, Konsgen D, Dietel M, Fiehn O: Mass spectrometry-based metabolic profiling reveals different metabolite patterns in invasive ovarian carcinomas and ovarian borderline tumors. Cancer Res 2006, 66:10795-10804

85. Hirayama A, Kami K, Sugimoto M, Sugawara M, Toki N, Onozuka H, Kinoshita T, Saito N, Ochiai A, Tomita M, Esumi H, Soga T: Quantitative metabolome profiling of colon and stomach cancer microenvironment by capillary 
electrophoresis time-of-flight mass spectrometry. Cancer Res 2009, 69:4918-4925.

86. Sreekumar A, Poisson LM, Rajendiran TM, Khan AP, Cao Q, Yu J, Laxman B, Mehra R, Lonigro RJ, Li Y, Nyati MK, Ahsan A, Kalyana-Sundaram S, Han B, Cao X, Byun J, Omenn GS, Ghosh D, Pennathur S, Alexander DC, Berger A, Shuster $J$ J, Wei JT, Varambally S, Beecher C, Chinnaiyan AM: Metabolomic profiles delineate potential role for sarcosine in prostate cancer progression. Nature 2009, 457:910-914.

87. Eisenberg-Lerner A, Kimchi A: The paradox of autophagy and its implication in cancer etiology and therapy. Apoptosis 2009, 14:376-391.

88. Maclean KH, Dorsey FC, Cleveland JL, Kastan MB: Targeting lysosomal degradation induces $\mathrm{p} 53$-dependent cell death and prevents cancer in mouse models of lymphomagenesis. J Clin Invest 2008, 118:79-88.

89. Sparks CA, Guertin DA: Targeting mTOR: prospects for mTOR complex 2 inhibitors in cancer therapy. Oncogene 2010, 29:3733-3744.

90. Loges S, Mazzone M, Hohensinner P, Carmeliet P: Silencing or fueling metastasis with VEGF inhibitors: antiangiogenesis revisited. Cancer Cell 2009, 15:167-170.

91. Paez-Ribes M, Allen E, Hudock J, Takeda T, Okuyama H, Vinals F, Inoue M, Bergers G, Hanahan D, Casanovas O: Antiangiogenic therapy elicits malignant progression of tumors to increased local invasion and distant metastasis. Cancer Cell 2009, 15:220-231.

92. Ebos JM, Lee CR, Cruz-Munoz W, Bjarnason GA, Christensen JG, Kerbel RS: Accelerated metastasis after short-term treatment with a potent inhibitor of tumor angiogenesis. Cancer Cell 2009, 15:232-239.

93. Blagosklonny MV: Antiangiogenic therapy and tumor progression. Cancer Cell 2004, 5:13-17.

94. Tisdale MJ: Cancer cachexia. Curr Opin Gastroenterol 2010, 26:146-151.

95. Holmes S: A difficult clinical problem: diagnosis, impact and clinical management of cachexia in palliative care. Int J Palliat Nurs 2009, 15:320, 322-326.

96. McClung JM, Judge AR, Powers SK, Yan Z: p38 MAPK links oxidative stress to autophagy-related gene expression in cachectic muscle wasting. Am J Physiol Cell Physiol 2010, 298:C542-549.

97. Asp ML, Tian M, Wendel AA, Belury MA: Evidence for the contribution of insulin resistance to the development of cachexia in tumor-bearing mice. Int J Cancer 2010, 126:756-763.

98. Witkiewicz AK, Kline J, Queenan M, Brody JR, Tsirigos A, Pavlides S, Sotgia F Lisanti MP: Molecular profiling of a lethal tumor microenvironment, as defined by stromal caveolin-1 status in breast cancers. Cell Cycle 2011, 10:1794-1809.

99. Martinez-Outschoorn UE, Whitaker-Menezes D, Lin Z, Flomenberg N, Howell A, Pestell RG, Lisanti MP, Sotgia F: Cytokine production and inflammation drive autophagy in the tumor microenvironment: Role of stromal caveolin-1 as a key regulator. Cell Cycle 2011, 10:1784-1793.

100. Dang CV: Glutaminolysis: supplying carbon or nitrogen or both for cancer cells? Cell Cycle 2010, 9:3884-3886.

101. Wise DR, Thompson CB: Glutamine addiction: a new therapeutic target in cancer. Trends Biochem Sci 2010, 35:427-433.

102. Dang CV, Le A, Gao P: MYC-induced cancer cell energy metabolism and therapeutic opportunities. Clin Cancer Res 2009, 15:6479-6483.

103. Kaadige MR, Looper RE, Kamalanaadhan S, Ayer DE: Glutamine-dependent anapleurosis dictates glucose uptake and cell growth by regulating MondoA transcriptional activity. Proc Natl Acad Sci U S A 2009, 106:14878-14883.

104. Eng CH, Abraham RT: Glutaminolysis yields a metabolic by-product that stimulates autophagy. Autophagy 2010, 6:968-970.

105. Eng CH, Yu K, Lucas J, White E, Abraham RT: Ammonia derived from glutaminolysis is a diffusible regulator of autophagy. Sci Signal 2010, 3:ra31.

106. Marino G, Kroemer G: Ammonia: a diffusible factor released by proliferating cells that induces autophagy. Sci Signal 2010, 3:pe19.

107. Dey S, Guha M, Alam A, Goyal M, Bindu S, Pal C, Maity P, Mitra K, Bandyopadhyay U: Malarial infection develops mitochondrial pathology and mitochondrial oxidative stress to promote hepatocyte apoptosis. Free Radic Biol Med 2009, 46:271-281.

108. Postma NS, Mommers EC, Eling WM, Zuidema J: Oxidative stress in malaria; implications for prevention and therapy. Pharm World Sci 1996, 18:121-129.

109. Siddiqi NJ, Alhomida AS: Status of hepatic oxidative stress and antioxidant defense systems during chloroquine treatment of Plasmodium yoelii nigeriensis infected mice. In Vivo 1999, 13:547-550.

110. Solomon VR, Lee H: Chloroquine and its analogs: a new promise of an old drug for effective and safe cancer therapies. Eur J Pharmacol 2009, 625:220-233.

111. Murchison EP: Clonally transmissible cancers in dogs and Tasmanian devils. Oncogene 2008, 27 Suppl 2:S19-30.

112. Thomas R, Rebbeck C, Leroi AM, Burt A, Breen M: Extensive conservation of genomic imbalances in canine transmissible venereal tumors (CTVT) detected by microarray-based CGH analysis. Chromosome Res 2009, 17:927-934.

113. McCallum H, Jones M, Hawkins C, Hamede R, Lachish S, Sinn DL, Beeton N, Lazenby B: Transmission dynamics of Tasmanian devil facial tumor disease may lead to disease-induced extinction. Ecology 2009, 90:3379-3392

114. Kreiss A, Tovar C, Obendorf DL, Dun K, Woods GM: A murine xenograft model for a transmissible cancer in Tasmanian devils. Vet Pathol 2011, 48:475-481.

115. Copper HL, Mackay CM, Banfield WG: Chromosome studies of a contagious reticulum cell sarcoma of the Syrian hamster. J Natl Cancer Inst 1964 33:691-706.

116. Banfield WG, Woke PA, Mackay CM, Cooper HL: Mosquito transmission of a reticulum cell sarcoma of hamsters. Science 1965, 148:1239-1240.

117. Gartner HV, Seidl C, Luckenbach C, Schumm G, Seifried E, Ritter H, Bultmann B: Genetic analysis of a sarcoma accidentally transplanted from a patient to a surgeon. N Eng/ J Med 1996, 335:1494-1496.

118. Rebbeck CA, Thomas R, Breen M, Leroi AM, Burt A: Origins and evolution of a transmissible cancer. Evolution 2009, 63:2340-2349.

119. Rebbeck CA, Leroi AM, Burt A: Mitochondrial capture by a transmissible cancer. Science 2011, 331:303.

120. Villanueva T: Metabolism: the mitochondria that wag the dog. Nat Rev Cancer 2011, 11:155

121. Stettner N, Brenner O, Eilam R, Harmelin A: Pegylated liposomal doxorubicin as a chemotherapeutic agent for treatment of canine transmissible venereal tumor in murine models. J Vet Med Sci 2005, 67:1133-1139.

122. Spees JL, Olson SD, Whitney MJ, Prockop DJ: Mitochondrial transfer between cells can rescue aerobic respiration. Proc Natl Acad Sci U S A 2006, 103:1283-1288.

123. Chen El, Hewel J, Krueger JS, Tiraby C, Weber MR, Kralli A, Becker K, Yates JR 3rd, Felding-Habermann B: Adaptation of energy metabolism in breast cancer brain metastases. Cancer Res 2007, 67:1472-1486.

124. Martinez-Outschoorn UE, Prisco M, Ertel A, Tsirigos A, Lin Z, Pavlides S, Wang C, Flomenberg N, Knudsen ES, Howell A, Pestell RG, Sotgia F, Lisanti MP: Ketones and lactate increase cancer cell "stemness," driving recurrence, metastasis, and poor clinical outcome in breast cancer: Achieving personalized medicine via Metabolo-Genomics. Cell Cycle 2011, 10:1271-1286.

125. Bonuccelli G, Tsirigos A, Whitaker-Menezes D, Pavlides S, Pestell RG, Chiavarina B, Frank PG, Flomenberg N, Howell A, Martinez-Outschoorn UE, Sotgia F, Lisanti MP: Ketones and lactate "fuel" tumor growth and metastasis: Evidence that epithelial cancer cells use oxidative mitochondrial metabolism. Cell Cycle 2010, 9:3506-3514.

doi:10.1186/bcr2892

Cite this article as: Sotgia $F$, et al: Understanding the Warburg effect and the prognostic value of stromal caveolin-1 as a marker of a lethal tumor microenvironment. Breast Cancer Research 2011, 13:213. 